\title{
Food as a Major Cite for Culture and Identity: A Select Reading of Frances Mensah Williams' Novel From Pasta To Pigfoot
}

\author{
Sathiya Priya ${ }^{1} \mathrm{~T} \&$ Shilaja.C.L ${ }^{2}$ \\ ${ }^{1}$ Sathyabama Institute of Science and Technology. \\ Email: sathiyapriya.english@sathyabama.ac.in \\ ${ }^{2}$ Stella Maris college for Women
}

First published July 19, 2019

\begin{abstract}
It is an unending attempt for the immigrant community to come out of the entanglement of identity issues, especially in postcolonial settings. Apparently, it appears to be more complicated for the second or third generation subjects of the settler's family for they have zero firsthand experience of their home culture. Such issues of complicated identity are widely addressed in many of the postcolonial narratives and this paper attempts to trace similar kinds of concerns through the specific lens of food. The reason for which food is chosen as a focal point is that food stands as a striking symbol through which multiple aspects of the society like culture, ethnic identity, gender roles, politics, social order, etc., can be vastly interpreted. The novel From Pasta to Pigfoot written by Frances Mensah Williams has a greater scope on analyzing such concepts of culture and postcolonial identity through the representation of food. A deeper examination on the role of food played at various layers throughout the novel allows us to understand that the concepts revolved around the food like cooking, dining, choice of food, eating, food manners and many other culinary aspects subject to challenge an individual's identity at a greater level. This article also seeks to examine the ways in which this complexity of individual identity could be at least balanced if not completely resolved.
\end{abstract}

Keywords: Food, culture, identity, ethnicity, postcolonial, multiculturalism.

\section{Introduction}

Food, apart from its basic biological function, operates at different layers which are gaining momentum in research in the recent years. Every single human satisfies the need of his body by ingesting food into it. One can assume that food comes easily on the platter but the reality is that every single grain that one consumes involves a lot of politics before it gets into the body. Historians, anthropologists, psychologists and sociologists had shown a greater interest in such deeper connections and cleared the air by exposing the connection between food and different variables like class, gender, society, ethnicity, religion, culture and politics. It is also important to understand that food is not a separate entity by itself but other related aspects like production, preparation, dining and eating should also be thoughtfully considered within the realm of food studies.

\footnotetext{
(c) AesthetixMS 2019. This Open Access article is published under a Creative Commons Attribution Non-Commercial 4.0 International License (http://creativecommons.org/licenses/by-nc/4.o/), which permits non-commercial re-use, distribution, and reproduction in any medium, provided the original work is properly cited. For citation use the DOI. For commercial re-use, please contact editor@rupkatha.com.
} 
Structuralists, anthropologists, historians and psychologists have presented a varied opinion on food discourse which allows us to dig deep the connection between foodways and individual identity. One of the pioneers in the field, the structuralist Levi Strauss has postulated a powerful theory in his path-breaking work The Culinary Triangle (1966) where he reveals on how culture deeply influences the mode of cooking. He classifies food into three aspects such as raw, cooked and rotten, within which he explains how the three types of cooking like boiling, roasting and smoking are implied upon food transformations. He represents raw as natural and "unmarked", cooked as a product of cultural transformation and rotted as a product of natural transformation. The structural oppositions he uses in this culinary triangle can be implied to human characteristics in general and he thus compares cooking to that of the language. "Cooking is a language through which society unconsciously reveals its structure" (Levi-Strauss 1979, 495). Holding to his assertion, the pattern of commonalities, differences and evolution among the postcolonial communities can also be revealed through cooking and food practices.

In recent decades the social scientists and psychologists have begun paying significant attention to food studies. They started focusing on psychological influence on food choices, the relationship between mood and food choice and food cravings, societal influence on food choices like advertising, marketing and media, food choices based on different age groups, the influence of changes in a location like diaspora, etc.,(Shepherd 2006).

\section{Food as Symbol}

Food also acts as a powerful symbol to represent identity and cultural meanings. Mary Douglas stands as an important contributor for her theory of semiotics of food as a social code. She asserts food as an important code to maintain social order and for individual or group identity. If food is treated as a code, the messages it encodes will be found in the pattern of social relations being expressed (Douglass 1979, 231). Furthermore, the Indian-American anthropologist, Arjun Appadurai in his seminal work Gastro politics in Hindu South Asia, having South Asia as the context, has proved that food functions as a strong semiotic device arbitrating the social values.

The general semiotic properties of food take particularly intense forms in the context of gastro-politics - where food is the medium, and sometimes the message, of conflict. Food serves two diametrically opposed semiotic functions: it can either homogenize the actors who transact in it, or it can serve to heterogenize them. (Appadurai 1981, 494)

Appadurai discusses the food politics that happens in the Tamil Brahmin households based on age, gender and family settings. During festivals and food gatherings ambiguity arises because the first preference for food consumption is given to the husband's family than that of a wife's side. Nevertheless, he argues that the elaborate rules and south Indian rituals facilitate the homogeneity, holding food substance as its solidarity. Hence food as a powerful semiotic device can both heterogenize people meant for its deciding authority in social groups and at the same time homogenize people on bringing them together on a social and religious jamboree. He argues that within this facet of food as a symbolized medium both social pleasure and anxiety emerge that questions an individual's identity, especially in a culturally diverse country like India.

An individual's connection with food is completely personal. This implies the way one experiences a particular dish is completely different from that of the other experiencing the same. Hence eating is completely a personal and individual action which, however 'involves an anxious encounter between self and world, or the known and the unknown' (Oyangen 2009,323). This anxiety that involves around food consumption is deciphered by a particular pattern of 
gastronomy framed and sanctioned by the society within the dynamics of a culture. Eventually, an individual's consumption relies on the framed pattern of food culture that facilitates in settling any confusion or anxiety related to the choice of food and eating habits. As a result 'culture regulates what and how one must eat' (Fischler 1988).

\section{The Politics of Food in From Pasta to Pigfoot}

When this persistent pattern of food consumption that belongs to one particular community, culture or a place is disturbed, the anxiety between the self and outside world proliferates which leads to the state of ambivalence. The question of identity necessarily arises at this point of ambivalence which is more intriguing, particularly in the case of immigrants. Considering the setting of the novel From Pasta to Pigfoot as postcolonial, Frances Mensah Williams deals with foodways and food politics differently, focusing more on the problems related to gastronomy and alimentary aspects. The colonist experience of the central character Faye in this novel helps us to understand the complexity of foodways in immigrant conditions. Food in this novel stands as a symbol mainly representing transnational culture, pluralism and multiculturalism within the framework of post-colonialism. All the food images in the novel attest its role in conditioning people's way of life, "ways in which people understand themselves, identify with others, and communicate their desires, beliefs, and claims to status" (Oyangen 2009, 325).

The novel From Pasta to Pigfoot begins with the circumstances where the protagonist Faye faces the conflict when she is criticized by her culturally conscious boyfriend Michael for being culturally lacking. Faye Bonso is initially confused about not knowing her exact problem but later realizes that it is her cultural hybridity that continuously puts her in the state of ambivalence. Faye and her brother William are migrated from Ghana to London along with their father Dr. Bonso after their mother's demise during their early childhood. They were brought up totally English except for a few native practices insisted by Dr. Bonso. Also, they were raised by an English housekeeper Ms. Lottie, hence being completely alienated from their roots. Mensah Williams adds more flavor to the story by presenting a hint of reverse colonialism at many occasions, one for which she makes the English character Ms.Lottie being cheated by Olu, a Nigerian doctor, showing Ms. Lottie as a housekeeper of a colour family and at another instance, portraying Dr. Bonso as a leading and inevitable figure in his research field in the western land. Ms.Lottie takes up the role of a central female figure in Dr.Bonse's family but has no idea of Ghanaian culture, language, lifestyle or foodways, thus not able to expose the kids to their ethnicity though she is intensely affectionate and caring. In a diasporic setting 'home' is recreated through two major basic things- language and food through which they stay in touch with their native culture. The functioning scope of language or food in an immigrant family is directly influenced by "parental attitudes, community demography, frequency of consumption, fluency in the language and the frequency with which a person visited their heritage country" (Weller 2014, 7). When it comes to Dr. Bonso's family both mother tongue and mother food are denied to his kids with the absence of their mother. Being motherless, Faye and William are not associated with their cultural roots because it is the mother figure who always provides ethnic affiliation, especially through self-cooked native foods in a foreign land. Tulsi Srinivas on her observation in the foodways of cosmopolitan Indian family in Bangalore and diasporic Indian family in Boston have noted that gastro-nostalgia is directly connected to mother figure and "one of the key ingredients of the descriptions of foods that appeal to gastro-nostalgia is the evoking of 'home cooking' or as 'mother made it' " (Srinivas 2006, 210), for which Faye has no access in her London home. However, Dr. Bonso's firmness on following Ghanaian tradition is not less than a reminder 
of their ethnicity in the household, especially his insistence on eating together on Sunday mornings and making traditional dishes on important festival days. Dining together being an important facet of foodways stands as an only hold of ethnic habits in their home and the parody is that the food on the table is, however, English like bread, pasta, and black coffee.

Initially, as they came to London, they faced a lot of racial tribulations and it was a double trauma for them of losing their mother in the first place and migrating to a new country in the second place. They were put in an exclusive Hampstead primary school where the white children refused to play with them and called them dark skin 'dirty' (Mensah Williams 2015, 54). In spite of all the curt remarks they faced, Dr.Bonso refused to put his children in a culturally mixed school, because from his point of view a standard education in an elite school is the priority that cannot be compromised for "spurious ethnic considerations" (Mensah Williams 2015, 55), the typical diasporic mindset which could be called as "cultural programming for economic success" (Kibria 2003, 11). As a young child, during her miserable times of racial hurts all she could recall was the life in Ghana, "especially the pungent smell of spicy food" (Mensah Williams 2015, 54) and feels gastro-nostalgic but now as a grown up all the native memory appears to be a "distant blur with occasional windows of clarity" (Mensah Williams 2015, 53) for they have totally lost in touch with their cultural roots.

As the days passed on, gradually they managed to survive the cultural differences and assimilated into the mainstream culture. Both Faye and William end up totally English, making friendship with whites, working with whites and being recognized one among them, however with a tinge of uncertainty buried deep inside their hearts as they confront ethnic complexities now and then. The plot takes a twist and the identity issue comes to the limelight when Faye falls in love with Michael hoping that she will discover her culture and self through him which would help to fill the existing cultural vacuum in her. In the contrast, she faces failure and breaks up with him for he made her feel more insecure and demeaning her as culturally bankrupt. This incident makes her think seriously about her roots and she goes to Ghana on a vocation where she is warmly received by Asante family and friends. She also happens to visit her mother's native place Ntriso and witnesses a lot of Ghanaian tradition and rituals. All these cultural revelations make her feel more confident than ever before and help her to take a stand in her personal and social life. Embedded in all the incidents, foodways travel from the beginning to end of the novel highlighting the cultural conflicts and reunion. The author, in fact, draws upon many traces of personal food system at different landscapes like urban London, Urban Ghana and rural Ghana along with the evolution of Faye's self-image.

At the outset of the novel, in London, Faye is fonder of the food Pasta which she prefers to cook on a date with her boyfriend Michael which is quite contradictory to his taste and choice who always keeps close to his ethnic consciousness. In yet another social gathering at Luther and Philomena's house, and with other Caribbean friends of Michael, Faye fails in her foodways for she prefers English food and dodges the native food. In a diasporic community, showing hospitality by serving native foods in an ethnic gathering, associates them closer to their homeland and develops a sense of national identity. "The fact that hospitality, to strangers or to kin, has to be narrated and re-narrated, then, reflects the reality that it is an important part of the construction of an honorable personal, local or national identity" (Sutton 2001,51). On the contrary, when Faye was asked for her choice of drinks by Philomena, she chose coke for native rum, upshot everyone barged on her making her feel culturally unfit and forced her to drink rum.

I'd like a rum and coke then, please,' Faye said politely... 
Jiggy: "Huh! What's that Faye? You want to mix our sacred nectar with a Coca- Cola drink?...' Michael, what have you been teaching her all this time?'. (Mensah Williams 2015, 22-23)

A tension between an individual need and cultural necessity is created at this point and anxiety arises inside Faye and constantly articulates her fear of being ignored and disregarded by people of her own race and color. Later when she talks about the above incident with her brother William she expresses her fretfulness by quoting one of Michael's friend's conception on her for the food choices."He basically accused me of being a slave to the colonialist mentality and cut off from my cultural roots." (Mensah Williams 2015,49).

As in the case of Faye, it is often noted that the choice of food is imposed on an immigrant individual based on the host's assumptions during the communal gathering more than the individual's own preference, leaving the guest in contempt. Robert Georges condemns this sort of action drawing examples from his own personal experiences and proposes his ideology regarding food choice and social identity:

We and others select and reject certain foods, prepare the selected foods in particular ways, and serve them to specific individuals because we identify them as ourselves as Southerners, natural food addicts, men or women, old or young; and our decisions may be made unilaterally rather than cooperatively, regardless of the nature or the source of the identities we ascribe to others and conceive them to ascribe to us" (Georges 1984, 256).

It makes the point that when food choice is not natural but forced in case of ethnicity, the search for identity gives a more bitter experience rather than satisfaction and pleasure, which is true in every situation of Faye on the encounter with her ethnic group. Subsequently, Faye tries to patch up with Michael for her past unconvincing behavior by accepting his invitation to review an authentic Caribbean restaurant Pigfoot Etcentra again with the same group of friends whom they met at Philomena's house. There are particular moments throughout the novel where the author mentions the booming culture of ethnic restaurants in a city of mainstream culture like London. Migration makes increased connections and communications among multiple cultures and Homi Bhabha calls this place of intersection as a point of hybridization and breeding ground of new cultural forms: "These 'in-between' spaces provide the terrain of elaborating strategies of selfhood - singular or communal-that initiate new signs of identity, and innovative sites of collaboration and contestation, in the act of defining the idea of society itself" (Bhaba 1994, 1-2). Hence "globalizing process are enacted and embodied in the practices of vernacular culture" (Turgeon and Pastinelli 2002, 249). Faye not being aware of this strategy and being innocent of the ethnic globalization, expresses her unwillingness on dining in the restaurant, for which Michael readily dismissed her with a cultural statement, "Maybe you don't eat this kind of food in your cosy Hampstead world, but down here this is part of the culture" (Mensah Williams 2015, 96). Invariably, food remains as a tool for identity maintenance. Faye's idea of mingling with the people of her ethnic group to retrieve her identity can be considered as an 'imagined fantasy of an immigrant' (Rushdie 1991). The situation gets even worse when Michael's ex-girlfriend Jasmine joins the blaming troop that is armed against Faye for culturally lacking. Faye remains culturally alienated from the rest of the people and feels so miserable. Aggravating the situation, Faye ended up ordering Pasta a symbol of western ways in a Carribean restaurant for she couldn't stand either the dish Pigfoot or the people around her. "...She simply couldn't stand Pigfoot. The texture of the bony pink meat didn't appeal to her in the slightest and actually left her feeling slightly nauseous." (Mensah Williams 2015,102). 


\section{Food for Identity}

At this juncture, food plays a vital symbol on creating an identity batch for Faye on who originally she is. Hence food is loaded with a lot of meaning constituting " a system of communication, a body of images, a protocol of usages, situations and behavior" (Barthes 1961,24). Most commonly in case of immigrants, they suffer from neophobia in trying the new foods of foreign land but for Faye it's reverse as she feels neophobic towards her native foods since she is more prone towards mainstream western culture, which shows the lack of attachment for the second generation immigrants towards their culture (Gans 1996).

Following this incident Faye once for all decides to end her relationship with Michael. However, she realizes that there is a truth in Michael's point and she feels a cultural void inside her. She opinionates this problem to her friends and family and that makes her father realize that he has neglected their cultural needs and he decides to send her to Ghana on a vocation.

For a second or third generation immigrant, this kind of diasporic tourism where the immigrants visit their homeland frequently is imperative for it keeps them connected to their native culture, language, people, foodways and lifestyle. Researchers have proved that the attachment of second and third generation immigrants to their homeland is directly proportionate to their frequent visits to their heritage country. (Huang et al 2013). That proves that Faye and William are totally cut off from their cultural roots primarily because they have never taken diasporic tourism ever since they left their homeland. As she prepares for her trip to Ghana, anxiety dwells in her because she had doubts about being accepted in Ghana as one among them. On one side Faye's major motto is to overcome the state of cultural limbo, the inbetweenness, the confusion of belonging nowhere by having firsthand experience in her native Ghana, on the other hand, she is terrified on her encounter with her homeland with the uncertainty of her reception.

On Faye's expedition to Ghana food again plays a vital role in the process of her selfmaking. During her flight journey, she recollects the farewell dinner given by her best friend Caroline with exquisite western dishes and remembers Caroline's brother Dermot teasing her for her food choice, "Don't go asking for pasta everywhere you go either, for God's sake" (Mensah Williams 2015, 148). The appropriateness of food choice remains significant with that of the identity equation. As a London brought up, divergence from her preferred practice of western food consumption is unthinkable. She remains so distant to the knowledge of native food and moreover developed an aversion towards native food like Pigfoot. This inappropriateness of her food choice and the idea of culturally messing up makes her even more terrified on her visit to Ghana. Among the codes of symbol that the food carries, the principal one is national identity which is more related to the appropriateness of food choice to one's national cuisine. Individuals of the same ethnic background relate themselves based on their common food choice, eating habits and taste and with which they distinguish themselves with other national groups as "to eat is to distinguish and discriminate, include and exclude. Choices establish boundaries and borders" (Belasco 2002, 2).

Clouded with doubt of her ethnic inappropriateness Faye reached Ghana, but to her relief, she was well received and treated with warmth by her relatives and friends but not without the occasional encounter of cultural onslaughts that happened especially through food. She encounters native food culture in may circumstances that help her to understanding the function of her native cuisine and alimentary aspects. But to her surprise, she has witnessed the tremendous influence of modernization in the city of Ghana which in many aspects equal to that of London. Especially in the case of the food industry, available of western and packaged food 
items and well equipped modern kitchens show that Africa is way too far from its stereotypical portrays in postcolonial narratives. The author Mensah Williams seems so deliberate in presenting the actual condition of Africa and she remarks that "I dispute that the book romanticizes Ghana but rather I am of the view that it depicts the other side of Ghana and arguably the Africa that is not typically portrayed in mainstream narratives. The fact that it is not often written about doesn't mean that it doesn't exist. I focused on the Ghana that I love to share with people" (Osei-Bempong,2016). This commensality between West and Africa stands as a great consolation for Faye as she finds familiar things and practices in Ghana like western food, clothes and especially the language. It's a great comfort for her in the host family of Mr. \& Mrs. Asante, for their conversational language in their family is predominantly English.

In her attempt to finding a bond with her roots, she feels successful when she discovers unexpected connections to her mother especially through her food behavior which can be witnessed in her aunt Amelia's comment, "I see you are a coffee drinker, not a tea person...Your mother was a coffee drinker too, you know," (Mensah Williams 2015, 201). This solidarity that she discovers between herself and her mother in terms of food choice, attitude, clothing makes her initially to connect herself more with her mother and then to her motherland.

Food particularly is seen as a prosperous domain to explore the complexities of memory in an individual (Holtzman 2006) and the dish Pigfoot in this novel stands as a symbol of Faye's complex memory. She refuses to consume the dish Pigfoot on several occasions later in Ghana for her aversion towards that particular dish is strongly rooted in her memory. The dish has been psychologically related to her earlier unpleasant experience with Michael and his friends. In the later part of the story, at a friend's party in Ghana, Faye was even penalized for her inability to adapt herself to the native food, being accustomed to English food habits. Clarrisa, a fashion modal at Ghana who envies Faye for stealing the heart of Clarrisa's ex-boyfriend Rocky, finds Faye's dislike towards Pigfoot and she exploits the situation to culturally humiliate her. "Do you know how to eat our local food, Faye-Is it?"...Pointing at Pigfoot, 'I'm sure you'll love this, Faye; it's one of our most popular dishes." (Mensah Williams 2015, 319). Having had a bad experience surrounded by Pigfoot back in London, Faye feels so vulnerable and all her so far gathered confidence on her cultural equation in her homeland is crumbled at the mention of this particular dish. Pigfoot gives her a series of shameful experiences and clings strongly to her image of ethnic identity from the beginning to the end of this novel and that makes her feel simultaneously at place and placeless. This shows that the representational meaning of food is directly connected to an individual's memory and personal experience (Lupton 1994, 668). When she desperately tries to blend with her ethnic group, ironically the memory of Pigfoot reinforces her otherness.

Later, when she explores Ghana with one of her Ghanaian friends Sony, he resolves to take her to one of the local restaurants that sell real Ghanaian food, 'not like those expensive bourgeois restaurants' (Mensah Williams 2015, 231) where the Asante family members usually take Faye to. Sony's statement about the foodways of upper-class bourgeois families shows that the native cuisine of Africa has been extremely mutated in urban places of Africa. This leads us to question how the concept of 'home' and 'ethnic identity' is constructed in an increasingly industrialized, corporatized, plural and transnational world of food(Srinivas 2006, 197), where the authenticity is uprooted. Interestingly, this sort of food industrialization and global food flow in the markets of developing countries like Urban Africa allows us to understand that the people of native land are in desperate conditions to reconstruct their identity, to show them as civilized, coping with time and taste and to highlight them as culturally forward. It could be taken as a binary opposition, given the situation that an immigrant is anxious about identity loss, whereas the native people are 
ready to modify their definitions for identity in personal and social settings to prove them as advanced. For them, the real identity is to evolve and stand in par with developed countries by challenging the global market and foodways being a major part of it with other aspects like industrialization and economy. And this binary opposition can be further understood by realizing the fact that the effect of globalization is opposite to the effort of cultural homogeneity model attempted by the diasporic community. (Srinivas,193, 2006, As mother made it). Globalization theorists have made the world realize that it is important to locate and understand these spots where the cultures interact and make "the local globalized and the global localized" (Comaroff 1999,32). This understanding of culture being blend, made fluid, flexible and manipulative brings a lot of self-realization to Faye about her identity conflicts.

Showing the food practices of different geographical locations, this novel takes us to rural Africa, Ntriso- the birthplace of Faye's mother Annie. Faye travels to Ntriso, where she meets her extended maternal family and witnesses the traditionally performed funeral rituals that include a lot of food and dance. As she visited the rural settlements of Africa she observes the vast differences between rural and urban Africa. In the kitchen space, Faye observes that the rural kitchen of West Africa is not invaded by the food industrialization so far, which sheds positive light as the traditional cooking and eating habit remains the same. The kitchen is not modernized but with simple native tradition and native foods like jollof rice, kontomire, fried fish, nicely boiled yam, kenkey (Mensah Williams 2015, 367).

On her visit to Ntriso which she now thinks like a real home, a lot of self-realization happens and overcomes all her inhibitions about her self-image and ethnic identity. When her aunt Amelia observes the change in Faye she says that Faye looks more confident than when she first arrived, for which Faye responds, "Yes, I think you're right. I've only been in Ghana or three weeks, but it feels so much longer. And I am much more confident now that I know more about my country and my culture' (Mensah Williams, 448). Apparently, this kind of revisit and tourism to their homeland helps the diasporic community not only to find their roots but also paves the way to their identity change and self-realization(Ebron,1999).

After witnessing all the native traditions of Africa and its transformation in the urban area she realizes that she had been so harsh on herself not knowing the facts about evolving culture and identity. On her diasporic tourism, she renewed her ties to her homeland and understands where she exactly stands in terms of her identity in a transnational setting. She is so imbibed into the native culture that she ends up eating the dish Pig foot naturally without any aversion. 'Amma, do you realise that I've just eaten a plate of Kontomire with pigfoot and I didn't even notice?' (Mensah Williams 2015, 458). This shows how culture can condition an individual's eating habits through various stages. Even seemingly "natural" feelings of disgust and repulsion are culturally conditioned to some extent ( Oyangen 2009, 326). The association of food to an individual is socially constructed and in case of Faye she imbibes the western food culture in the beginning which is constructed by her western surroundings and later when she is exposed to her native culture the meaning changes with her experience of native foodways which shows that food habits are also socially constructed and transmitted. Moreover, when she realizes her natural acceptance of her native food she feels like her identity is regained. "The retrieving of the self through the eating of the cuisine of one's caste, ethnic group, region and locale, becomes a precious experience" (Srinivas 2006, 209).

Food again stands as the symbol of pluralism, for Faye neither detaches herself from the western food nor attaches to her native food completely on her return from Ghana, only that she had enough awareness about her ethnicity. On seeing pasta at Caroline's home she expresses her 
excitement about her favorite food. 'Ooh, I've missed eating pasta,' she exclaimed happily. 'This looks great. Can I start?' (Mensah Williams 2015, 483). She understands that the most import aspect of identity is being oneself and having a self-image irrespective of ethnicity and place, which she reflects on her unexpected meeting with her ethnic rival Jasmine. "if you have enough sense of who you are and where you are from, it doesn't matter in the slightest what colour your friends are because, as any intelligent person will tell you, friendship doesn't come in colours." (Mensah Williams 2015, 509).

\section{Conclusion:}

The question of disjunction between the immigrant communities and the ethnic culture is well answered by the author through food symbols and its potential of permeability. With geographical shifts from the city of London to the city of Ghana and then to rural Africa, the novel witnesses the variations of gastronomy and helps Faye 'to understand her personal and collective identity' through food(Narayan Uma 1997, 161). At the end of the novel, through Faye, the author voices out that identity is all about evolution and acceptance and it is not bound to a particular variety of food, habit or culture.

You know, Lottie, Michael made me feel as if I could only be culturally acceptable if I spoke a certain way or ate a particular type of food. It took me a while to sort things out for myself, but I know now that eating all the pasta in the world doesn't make you white, any more than eating all the Pigfoot in the market can make you black. (Mensah Williams 2015,513)

Most importantly, the identity issue is sorted out for Faye with a vast awareness and gaining the knowledge of the food and culture of her ethnic group, mainly narrowing it down to her locale and family. In addition to that, with an awareness that in diasporic conditions where amalgamation has become the norm of life she understands that it is impossible and "increasingly difficult to attach human identity and meaning to a coherent culture" (Clifford 1988, 95). Further, this complex yet unavoidable condition of syncretism is significant as ' most immigrants both resist and participate in their own displacement from old food habits, trying to find an acceptable combination of tradition, acculturation and innovation" (Oyangen 2009,341). Mensah Williams being a multiculturalist herself suggests that the balance can be achieved through the acceptance of pluralism and at the same time being aware of one's cultural roots and she achieves the balance of cultural identity by enacting it through food consumption and making a point that an immigrant's food preference is subject to change very easily in an individual's life cycle. The author resolves the conflict of food consumption by fuelling the plot with food meta-narratives (Srinivas. T 2006,193) and eventually landing with the tolerance of pluralism in transnational conditions and thus food as a powerful symbol articulates and meets the desire of the character Faye in terms of her identity conflicts. In the context of pluralism, one must agree with the words of Knut Oyangen who postulates on the gastro dynamics of displacement that " To achieve a symbolic connection between the old home and the new one was more important than slavishly to follow tradition. To act always and everywhere, in the same way, is contrary to human nature." (Oyangen 2009, 348). Supporting all the above assertions, Benedict Anderson's theory of imagined community helps us to understand that the national identity associated with national cuisine itself is socially constructed by people's imagination that they identify themselves as a part of a group (Anderson 1985). 


\section{References:}

Anderson, B. (1985). Imagined communities: Reflections on the origin and spread of nationalism. London: Verso Ed.

Appadurai, A. (1981). Gastro-politics in Hindu South Asia. American Ethnologist. 8.3:494-511.

Barthes, R. (2013). “Toward a Psychosociology of Contemporary Food Consumption." In Food and Culture: A Reader, edited by Counihan, C., and Van Esterik, P, 26. New York: Routledge.

Belasco, W. J., \& Scranton, P. (2002). Food nations: Selling taste in consumer societies. New York: Routledge.

Bhabha, H. K. (1994). The Location of Culture. London: Routledge.

Comaroff, J., \& Comaroff, J. (1999). Occult Economies and the Violence of Abstraction: Notes from the South African Postcolony. American Ethnologist, 26(2), 279-303. Retrieved from http://www.jstor.org/stable/647285

Clifford, James. (1988). The predicament of culture: twentieth-century ethnography, literature, and art.

Douglas, M.(1979). Deciphering a meal. Implicit Meanings: Essays in Anthropology, 249-275.

Ebron, P. A. (1999). Tourists as pilgrims: Commercial fashioning of transatlantic politics. American Ethnologist, 26(4), 910-932.

Fischler, C. (January o1, 1988). Food, self and identity. Social Sciences Information. Friedberg, Susanne. 2004. French Beans and Food Scares: Culture and Commerce in an Anxious Age. New York: OxfordUniversity Press.Gans, Herbert J.(1996). "Symbolic Ethnicity: The Future of Ethnic Groups and Cultures in America," in W. Sollors (ed.), Theories of Ethnicity: A Classical Reader, London, Macmillan Press Ltd.: 425-459.

Georges, Robert A. (1984). You Often Eat What Others Think You Are: Food as an Index of Others' Conceptions of Who One Is. Western Folklore 43(4):249-56.

Holtzman, J. D. (2006). Food and memory. Annual Review of Anthropology.

Huang, W.J., Haller, W. J. and Ramshaw, G.P.(2013)' Diaspora tourism and homeland attachment: an exploratory analysis', Tourism Analysis, VOl.18, No.3, pp.285-296.

Kibria, N. (2003). Becoming Asian American: Second-generation Chinese and Korean American identities. Baltimore, Md: Johns Hopkins University Press.

Lévi-Strauss, C.(1966) The Culinary triangle. Partisan Review, 33, 4, 586-595.

Lévi-Strauss, C.(1979). The origin of table manners: Introduction to a science of mythology: 3. New York: Harper \& Row.

Lupton, D. (1994). Food, Memo y and Meaning: The Symbolic and Social Nature of Food Events. The Sociological Review, 42(4), 664-685. https://doi.org/10.1111/j.1467-954X.1994.tboo105.X

Mensah Williams, Frances. (2015) From Pasta to Pigfoot. Ghana, Jacaranda Books Art Music Limited.

Narayan, U. (1997). DislocatinCultureses: Identities, traditions, and Third- WorldFeminismsm. New York: Routledge.

Oyangen, K.(2009) The Gastrodynamics of Displacement: Place-Making and Gustatory Identity in the Immigrants' Midwest. The Journal of Interdisciplinary History, 39(3), 323-348. Retrieved from http://www.jstor.org/stable/20143876

Rushdie, S. (1991). ImaginarHomelandsds: Essays and criticism, 1981-1991. London: Granta Books.

Shepherd, R., Raats, M., \& Nutrition Society (Great Britain). (2006). The psychology offood choice. Wallingford, Oxfordshire, UK: CABI in association with the Nutrition Society. 
1

Srinivas, Tulas i.(2006). International Journal of Sociology of the Famil y,Autumn2006, Vol. 32 Issue 2, p191. Retrieved from http://www.jstor.org/stable/23030195.

Turgeon, L. \& Pastinelli, M. (2002). "Eat the World": Postcolonial Encounters in Quebec City's Ethnic Restaurants. Journal of American Folklore 115(456), 247-268. American Folklore Society. Retrieved May 27, 2019, from Project MUSE database.

Weller, D. and DTurkon. . (2014). Contextualizing the Immigrant Experience: The Role of Food and Foodways in Identity Maintenance and Formation of First andSecond-generation Latinos in Ithaca, New York, Ecology of Food and Nutrition, DOI: 10.1080/03670244.2014.922071 